\section{ORIGINAL COMMUNTCATIONS.}

\section{THREE LECTURES ON THE CORRELATION OF PSYCHOLOGY AND PHYSIOLOGY.}

By DANIEL NOBLE, M.D., Visiting Physician to the Clifton Hall Retreat, near Manchester.

[Delivered at the Chatham Street School of Medicine, Manchester, June 1854.]

LECTORE III.

ON IDEAS, AND THEIR DYNAMIC INFLUENCE.

A roRx of consciousness which is higher still in the psychical scale than either sensation or emotion-THOUGHTexists also in the present sphere of existence, dependent upon organisation. Impressions received through the sensory and emotive ganglia influence thinking, and, in some sense, are essential to it; but thought itself is something beyond. These impressions constitute the material of ideasthose mental perceptions of objects and states of existence which form the basis of all positive knowledge, and which, once realised in the consciousness, can be recalled in memory, and thus be rendered available in the higher operations of mind.

It is physiologically certain that the intelligence, alike in the apprehension of things, qualities, and circumstances, and in the combination and arrangement of ideas, has cerebral instrumentality for its exercise; and evidence from all sources, anatomical, physiological, and pathological, points to the cortical grey matter of the brain, the vesicular neurine investing the convolutions, as supplying the requisite organic conditions. Mr. Solly has very appropriately designated this structure the hemispherical ganglia.

The progress of an impression from sensation, through intuition and representation, up to thought, has supplied to psychologists the occasion of much interesting speculation; but, in physiology, we need not attempt any such detailed analysis. An anatomical distinction, however, between the region of thought and that of sensibility can very fairly be established; and a certain aptitude, moreover, can be recognised in the encephalic structure for conveying the impressions of sense upwards to the hemispherical ganglia. White matter intervenes between the vesicular neurine of the sensory ganglia and that of the cerebral convolutions; the conscious impressions received by the former may be regarded as ascending along the white fibres, and, on the grey summit being attained, developing changes in its condition which minister to the intelligence. Ideas arise. If we reflect upon the processes that go on within our own minds, there is no difficulty in distinguishing between a sensation and an idea, or in marking the sequential origin of the latter. How often do we find that, when the full consciousness of sensation is obtained, the idea suggested by it does not follow until many seconds, or even minutes, afterwards. For example, you hear the utterance of certain words, as sounds; their signification does not strike you; no effort of attention is made; yet suddenly the sense breaks upon your intelligence. The correlated physiological phenomena may thus be stated. The auditory ganglia take up the sentient impression at once; its passage onwards to the seat of thought is delayed: presently, however, its natural course is freed, as if from some hindrance; and it attains the hemispherical ganglia, forming or awakening ideas in the mind.

Cranioscopic facts of a very obvious character render it probable that the anterior portion of these ganglia subserves, in an especial manner, the intellectual operations; that the upper region is associated very much with thoughts that are allied with the higher sentiments; and that the posterior division is connected mainly with ideas that refer themselves to the inferior affections and propensities of our nature. The doctrine of separate organs, however, for particular faculties of the mind, can hardly, in the present state of knowledge, be regarded as scientific truth.

The changes which, as sensations, are accomplished in the encophslon, develope ideas; and thees latter exert back again upon the organism a dynamic influence which has afforded to physiologists abundant material for curious and ingenious theories. The various bearings of this subject were beautifully worked out by Dr. Leycock, some jears ago, in : memoir on the Refiex Functions of the Brain, which was published in the British and Foreign Medical Review (vol. xix). In this memoir, Dr. Laycock discusses the hydrophobic gasp, and, after speaking of its induction by attempts to drink, traces the influence of mere ides in bringing about a like result. "The cerebral nerres", says he, "being analogous to the posterior spinal nerres, and the encephalic ganglia analogous to the spinal ganglia, the spectrum of the cup of water will traverse the optic nerves, and enter the analogue of the posterior grey matter in the brain, causing changes (ideagenous changes) corresponding to the idea of water; thence the series of excited changes will pass over to the analogue of the anterior grey matter, exciting another series (kinetic changes), by which the necessary groups of muscles are combined in action." The whole subject has also been admirably elucidated by Dr. Carpenter, in the last edition of his Human Physiology.

From the dominance of particular ideas, movements very often become excited when neither sensation nor emotion exerts any very appreciable influence, and when volition apparently exerts none at all. The morements in question seem to be quite as automatic-reflex as it were-as those which spring from impressions made upon the spinal, sensory, or emotive ganglia. In the transition state between sleeping and waking, there is great fertility of incongruous thought-disorderly groups of ideas, receiving nogovernance whatever from the will; yet, in these circumstances, muscular movements and other phenomena will frequently take place, respondent purely to the dominant idea. An attractive object is before the imagination, and a snatch is made at it. Here there is no selection among motives-no will; the act is altogether impulsive, prompted by the simple idea. In certain irregular kinds of sleep, and in somnambulism, spontaneously arising or induced by artificial processes, the mind can at times be literally played upon, so as to educe actions and movements contrived beforehand; these being suggested by communication of the correspondent idea, which becomes reflected in the outward conduct. Mr. Braid, in his hypnotic demonstrations, exhibits these phenomena in a very remarkable manner. He tells the sleeper, or sleep-waker, that he must raise from the floor some article before him; that, however, its weight. may defeat him; the subject of the experiment becomes ruled by the idea that he has to elevate some very ponderous substance; but it is a light pocket-handkerchief, probably. In such circumstances, I have seen muscular effort exerted in vain. It is intimated, in the hearing of the hypnotised person, that he has been insulted; the head becomes elevated in disdain. It is whispered that you are about to excite his benevolence, and he shows himself liberal in gifts; and so on. These things constitute illustrations of Dr. Laycock's reflex functions of the brain; and Dr. Carpenter, who appears to have worked out this matter very thoroughly, designates the phenomena ideo-motor. Ideo-dynamic would probably constitute a phraseology more appropriate, as applicable to a wider range of phenomena.

The dynamic influence which peculiar ideas and trains of thought exert, under circumstances in which volitional agency is imperfect or altogether in abeyance, is curiously exhibited in the origin and progress of numerous mental maladies; and, in instances wherein there may be no actual insanity, the singular effects which at times result, as ideodynamic phenomena, have, in their significance, important practical relations. On these accounts, I will furnish some still more striking illustrations of the influence mentioned.

A gentleman some years ago consulted me for sleepless nights. I formed the opinion that his ailment was attributable to fault in the stomach, and prescribed for him some bitter with an antacid. I thought it advisable, however, to commence with a free action of the bowels; and, 
with this vier, prescribed also eight grains of the compound extract of colocynth and two of calomel, made into pills, directed to be taken at bed-time. When I again saw the patient, he told mo the pills had given him an excellent night, for that he had slept beautifully. "But," I aid, "did they not purge you? They were intended to do so." "Why," he said, " as I had come to consult you for sleepless nights, and as the pills were to be taken at bedtime, I thought they were to make me sleep, and I did sleep; I was not purged at all." Now, instances of imaginary medicines producing the expected effect are common enough; doubtless, this is a circumstance to be considered in estimating the follies of homooopathy, and other such delusions of the hour; but here was a case in which, further, the ordinary action of powerful medicines was hindered by the dominance of an expectant idea.

The following case, having a similar significance, is quoted from Pechlin by Dr. Crichton, in his work on Ilental Derangement, published more than half a century ago:- "There was a student of my acquaintance at Leyden, who, either because I was too young, or because he wished to save his money, did not consult me, but took care of his own health. He had probably heard medical men say that purgatives were the best kind of remedies, and that pills were the best form for giving them. As he had been told that Fernelius was an author of great reputation, he borrowed him of me. I sent it to him. He looked in the index for the word pill; and, as he imagined that all pills were purges, he took the first as the best. These were the pil. cynoglossi, the dose one scruple, which he swallowed; and, after drinking two or three glasses of warm beer, waited the effect; and 10 ! it took place agreeably to the imagination, and he was thus purged by opium, hyoscyamus, crocus, and other anodynes and astringents."

The influence, under some circumstances, of particular directions of thought, in determining convulsions, especially in the female constitution, is familiar to all practitioners who have to treat hysterical and other such affections. On this account, detailed examples in illustration would be superfluous. "The effect", says Romberg, " of the imagination on seeing spasmodic movements, and even the mere recollection of them, may give rise to convulsions."

It is curious to witness the absorbing effects of dominant ideas in several of the forms of insanity. Common sensation sometimes appears to be temporarily paralysed. At this time, I have a female patient under my care, who, when deeply engrossed with her maniacal wanderings, appears to be quite insensible to pain. She will inflict upon herself bodily injury, as if from pure caprice; and display the most senseless indifference." "I have applied", says Esquirol, "blisters, setons, moxas, the actual cautery, to individuals strongly inclined to suicide, and to other melancholic patients, for the purpose of trying their sensibility: I have produced no pain; and some, after recovery, have assured me that they experienced no suffering whatever from these applications."*

The phenomena of mesmeric and natural somnambulism exhibit a parallelism with this state of things. With idiots, in whom ideas have such little force, mesmeric effects cannot be produced. At any rate, Dr. Guggenbühl, so philanthropically distinguished for his successful efforts in the improvement of cretins, has tried mesmerism; but, within his experience, not one has even been put to sleepa circumstance of itself suggesting that many of the phenomena of mesmerism result from the dynamism of dominant ideas.

The sudden and energetic communication of some striking thought to the mind exerts very singular effects, occasionally in suspending the power of particular muscles, and sometimes in the temporary abolition of consciousness. The Abbe Faria, celebrated in mesmeric history, is said to have put whole rows of persons into an unconscious state, through the vigour and determination with which he bade them "sleep!" A remarkable case is cited by Crichtont from the Prychological Magazine, a periodical publication of the last century-a case which shows the paralysing influence of an expectant thought communicated as shock. "In Kleische, a small village in Germany, belonging to Mr. V. T., a maid-servant of that gentleman's family was sent a short league from home, to buy some meat. She executed her orders correctly, and, as she was returning in the erening, she thought she suddenly heard a great noise behind her, like the noise of many waggons. Upon turning round, she observed a little grey man, not bigger than a child, who commanded her to go along with him. She did not, however, return any answer, but continued to walk on. The little figure accompanied her, and frequently urged her to go along with him. Upon reaching the outer gate of her master's residence, she was met by the coachman, who asked her where she had been, to which she returned a very distinct answer. He did not remark the little man, but she still continued to do so. As she was passing the bridge, he summoned her for the last time, and, upon her refusing to answer him, he told her, with a menaciug look, that she should be four days blind and dumb; and having said so, he disappeared.

"The girl hastened to her apartment, and threw herself on the bed, unable to open her eyes, or to pronounce a word. She appeared to understand all that was said, but could not make any answer to the questions which were proposed to her, except by signs. Everything was tried for her recovery by the family with whom she lived, but all was in vain. She was incapable of swallowing the medicines which were ordered for her. At last, on the expiration of the fourth day, she arose in tolerably good health, and narrated what had happened to her."

An anecdote, which illustrates the same psychological principle as that illustrated by the foregoing narrative, has been communicated to me by my friend and colleague, Dr. Whitehead, in these terms:- "The following is an account of the incident which happened to my old friend Mons. Boutibonne, and which I promised to give you in writing. Mons. B., a man of literary attainments, a native of Paris, served in Napoleon's army, and was present at a number of engagements during the early part of the present century. At the battle of Wagram, which resulted in a treaty of peace with Austria in November 1809, Mons. B. was actively engaged during the whole of the fray, which lasted, if I rightly remember, from soon after midday until dark. The ranks around him had been terribly thinned by the enemy's shot, so that his position at sunset was nearly isolated; and, while in the act of reloading his musket, he was shot down by a cannon-ball. The impression produced upon his mind was, that the ball had passed, from left to right, through his legs below the knees, separating them from the thighs, as he suddenly sank down, shortened as he believed to the extent of about a foot in measurement; the trunk of the body falling backwards on the ground, and the senses being completely paralysed by the shock. In this posture, he lay motionless during the remainder of the night, not daring to more a muscle, for fear of fatal consequences. He experienced no severe suffering; but this immunity from pain he attributu! to the stunning effect produced upon the brain and nervous system. 'My wounded companions', said he, 'lay groaning in agony on every side; but I uttered not a word, nor ventured to move, lest the torn ressels should be roused into action, and produce fatal hæmorrhage; for I had been made acquainted with the fact that blood-ressels wounded in this way did not usually bleed profusely until reaction took place. At early dawn on the following morning, I was aroused from a troubled slumber by one of the medical staff, who came round to succour the wounded. 'What's the matter with you, my good fellow ?' (Fr. 'Qu'a-t-il mon camarade ?) said he. 'Ah! touchez-moi doucement, je vous prie,' I replied, ' un coup de canon m'a emporte les jambes.' He proceeded at once to examine my legs and thighs; and giving me a good shake, with a ris de joie, he exclaimed, 'Faites-vous lever d'abord, rous n'arez rien de mal.' Whereupon I sprung up in utter astonishment, and stood firmly on the legs $w$ ich I 
believed had been lost to me for ever. I felt more than'ful than I had ever done in the whole course of my life before. I had not a wound about me. I had indeed been shot down by an immense cannon-ball; but, instead of passing through the legs, as I firmly believed it to have done, the ball had passed under my feet, and had ploughed away a carity in the earth benesth, at least a foot in depth, into which my feet suddenly sank, giving me the idea that I had been thus shortened by the separation of my legs. Voild ce que se fait-il le pouvoir d'imagination."

But not only will a certrin suspension of consciousness have place, and also of the energy of particular muscles, under the dynamic influence of ideas, but, moreover, in cases in which there is paralysis of function, an attentive and expectant thought will lessen for a time the morbid incompetency. I feel confident that temporary improvement in the hearing, which I have had occasion to witness, and frequently to hear of, in deaf persons subjected to mesmeric and other such unwonted processes of cure, has resulted altogether from the idea. Romberg relates the case of a patient whose leg and foot had become insensible, and in whom voluntary motion in those parts was all but abolished; he states, however, that, cren in the absence of all feeling, "the movement of the toes was facilitated by directing attention to them ;"* and within a like category must rank those well known instances in which local action becomes stimulated or depraved by the bestowal of excessive and anxious attention to particular organs or structures.

Another and habitual effect of ideas ensists in the production of variations in the cæncesthesis, or general sensibility ; thus giving rise to sentiment, affection, and passion. What indeed are the emotions but those states of consciousness which result from the reciprocal action of thought and sensibility? Particular ideas and sets of ideas operate upon this latter-upon the corporeal self-feeling - and accomplish peculiar changes therein ; and the impressions so received react back again upon corresponding trains of thought. If, as I have supposed, the so called optic thalami and corpora striata constitute the encephalic centres of emotion, we must, in these processes, regard them as acted upon from above-from the hemispherical gangliathrough the conducting agency of intercommunicating white fibres; just as, in emotion from more physical states, the same centres are supposed to be acted upon from below, through nervous filaments distributed to the organs and structures very generally. This hypothesis, says the learned and able author of $A$ Critical History of Modern Speculative Philosophy, "would harmonise extremely well with the whole observed derelopment of our knowledge, which, commencing with a physical impulse, appears next in the form of an incipient mental sensibility, and then expands into distinct notions or ideas; which ideas can then, in their turn, react upon the emotions. The position of the above mentioned ganglia at the base of the hemispheres corresponds exactly with the supposed function. They lie midway between the sensory ganglia on the one side, and the cerebral hemispheres on the other; and have fibres which communicate downwards to the one and upwards to the other." +

The inward feelings called forth by the agency of thought may be pleasurable or painful; but a statement that the emotions are constituted of the pleasure or the pain resulting from ideas does not exhaust the description. The late Mr. James Mill, the Rev. Sydney Smith, and some other psychologists, however, seem to reduce the emotional states to so very simple a definition. Benevolence, in this view of the case, comes to be regarded as the pleasure experienced in contemplation of the happiness of others; and fear, again, as the pain that flows from anticipation of evil; an analysis being attainable in the same way with all the emotions-passions, affections, and sentiments, alike.

Now, I think, upon reflection, that we must admit the pecifically distinct character of our varying states of con-

- Op. cital " Anclyis of the Intellectual Powers". sciousnees, as recognised in hope, fear, griof, pride, ranity, love, and other such inward experiences. Fo fou in : charucteristic manner under these several circuminances, quite irrespective of the pleasure or the pain that attende them. Fear is fear, and need not be exclusirely painful or pleasurable; love is love, and is only pleasurable under appropriate conditions; grief may be a "silent luxury", well as a poignant suffering. The psychical states of love, hatred, desire, aversion, joy, sadness, hope, despair, fear, audacity, courage, and so on, are modifications of the emotional sensibility provoked by thought, but separable from thought; such modifications being distinguishable amongst each other, regarded simply as feeling.

My meaning will be somewhat plainer if I cite the analogies afforded by external sensation. Hot and cold, hard and soft, moist and dry, as sensations, are distinguishable conscious experiences, called forth by the qualities of objects, but in themselves subjective states, pleasurable, painful, or neutral, as the case may be. The sense of taste furnishes probably the most complete and readily seized analogy. Sroetness is ordinarily pleasurable; to some, however, it is painful; and to others it is neither one nor the other. Occasionally, it is pleasurable, painful, and neutral, at different epochs of life; but at all times, and under all circumstances, sweetness is sweetness.

Gustatory impressions excited by sapid particles are sources both of pleasure and pain; they have always a distinct character about them; and the sense of taste would be very imperfectly described, in calling it the pleasure or the pain procured by contact of the tongue with sapid substances.

In a somewhat analogous manner, I regard the emotions, in their several states of sentiment, affection, and passion, as particular conditions of the concesthesis, determined usually by the presence of correspondent ideas, but capable, to some extent, of being experienced in their absence. If a dog bark loudly and unexpectedly, I startle, and immediately experience an emotion of fear distinctly prior to the idea of danger.

Who, that has seen much of nervous and mental maladies, has not had frequent occasion to witness emotional states of all kinds, without the presence of the ideas commonly inducing them? Hopefulness, joy, grief, and timidity, are perpetually encountered under these circumstances. "Some melancholic persons", says Esquirol, "are frightened at everything, and their life is consumed in constantly recurring anguish; whilst otherg are terrified by a vague feeling which has no motive. 'I am afraid,' say these patients, 'I am afraid.' But of what? ' $I$ don't know, but I am afraid." "*

It is within the experience of almost every one to have felt joy, sorrow, and anxiety, as the result of a dream, the ideas connected with which have entirely passed from the mind.

However speculative to many persons the physiology of the emotions here set forth may appear, it assists in the explanation of many pathological as well as physiological phenomena. When we regard the great ganglionic centres placed at the base of the hemispheres as an intermediate sensorium between purely mental states on the one side, and the consciousness of physical conditions on the other, it becomes intelligible that disordered bodily health should in most instances painfully impress the emotive sensibility; and that the influence, in ascending, as it were, should act upon the development of thought, giving rise to anxious and painful ideas. Or, to trace the process in reverse order: intelligence arrives suddenly of the death of some one beloved; the auditory ganglia, through the appropriate nerves, receive the sounds significant of the fact; the physiological change thus brought about has its influence conveyed onwards, and it attains the hemispherical ganglia; hereupon apprehension of the circumstance ensues, and the ideas developed work downwards upon the emotional centres, and violent weeping takes place as the physical 
crpreacion of grief; and disorder of the alimentary canal, - oren total derangement of the health, may follow as the consequence.

Particular feelings affect the bodily functions in methods ongeoting varying but special relations between individual crons and the emotive centres. "Fear," says Crichton, "is apt to occasion a diarrhos and incontinence of urine; anger affects the functions of the liver; grief disorders the stomich, and affects the lachrymal gland; sudden terror, when without hope, produces an almost complete palsy; and hope itself, when the attainment of the object is near, affects the organs of respiration, and causes a quick and powerful distribution of blood throughout the whole body."*

At first sight, there may seem to be an incompatibility between readily observed cranioscopic facts and the doctrine which places the region of thought in the hemispherical ganglia at large, rather than in the anterior division exclusively. And, indeed, to those who have never had faith in the details of phrenology, some peculiar connexion of the forehead with the intellect must appear to be highly probable. If, however, we examine this matter a little more closely, it will be obvious that, to whatever extent it may be thought necessary from the state of facts to admit an organology, as proposed by Gall, such organology would be quite reconcileable with the speculations advanced in this lecture.

In any division of the mental faculties that we may adopt, be it that of the phrenologists, or that of other psychologists, we must recognise in each faculty a twofold relation, an ideal and an emotional one. I will select for the illustration three phrenological faculties, the organs of which are among those represented as best established; I will take eventuality as an "intellectual power", veneration as a "moral sentiment", and destructiveness as an "animal propensity".

Now, eventuality, according to phrenological teaching, exercises itself with changing phenomena-with events; it procures the information, and reproduces it in memory. This, then, may be deemed its ideal function, accomplished through the organic instrumentality of vesicular neurine which invests the cerebral convolution placed behind a certain portion of the frontal boue. But, pending this exercise, there is modification of the conæsthesis, in the feeling of curiosity, gratified, or simply excited, or proroking to action, as the case may be. And this is the enotional function, organically active, we will assume, in that part of the corpus striatum which is in fibrous communication with the vesicular neurine before mentioned.

As regards veneration, there are persons of a reverent and devout tendency, who show it rather in the direction of their spontaneous and instinctive thinking, as it were, than in any great amount of derotional sensibility. The ideas of some individuals are always upon antiquity, upon great men, and upon the religious objects of reverence; and that, too, in cases in which there is but little manifestation of feeling. Here we have the ideal display of veneration. At other times, we see the excesses of devotional feeling, without much thought in regard to its objects; it is almost altogether emotion. In going to the anatomy, we know that vesicular neurine is at the central summit of the brain, communicating with similar matter at the base.

Destructiveness supplies a very obvious illustration of $\mathrm{my}$ meening. There is cruelty as thought, and wrath as feeling; when deliberate acts of poisoning and of incendiarism are perpetrated, when defenceless and helpless creatures are gratuitously tortured, destructiveness is mainly ideal, as it certainly is cold-blooded; but when there is furious passion - Then there is perturbation of the conmsthesis in deeds of violence-it is emotion. Anatomy, of course, gives the same explanation as in the previous illustrations.

But phrenologists commonly assume that, apart from the intelloct, the faculties each resolve themselves into kinds of feeling, pasaive in complacency and in dissatisfaction, and cetive in impulse; the share which ideas have in their pro cise manifestations, being attributed to co-operation of the intellect.

Now, it is certain that ordinary thinking goes on spontaneously very much; that there is an evolution of ideas habitually in play, which has very appropriately boen dosignated the mind's automatic working. It has been 80 designated because, in these circumstances, there is no rolitional co-ordination of thought, as in direct and active employment of the intelligence. This mental attribute has been denominated imagivation, not as signifying the imsgination exclusively which is poetic or inventive, but as that which constitutes the internal spring of all psychical imagery - of things imaged to the mind. Gall himself rocognises this general faculty of the mind in the following passages:-

"I call imagination the action of cvery faculty whatever that has place independently of the external world. The imagination is the creative power of each fundamental faculty. The imagination of the sense of places creates landscapes. The imagination of the sense of tones creates music. The imagination of the sense of numbers creates problems. The mechanical imagination creates machines.

"This explains how the same man may have a prompt and sure judgment relative to some subjects, and be almost imbecile in regard to others; how he may have a most lively and fertile imagination for certain matters, and be frozen and sterile for others."*

But, lastly, what is to be said of the will-that attribute of humanity which supplies the basis of moral responsibility, and the weakening or destruction of which constitutes so important a feature in psychological pathology? Certainly, the will can be regarded neither as a faculty apart from other states of mind, nor as mixed up particularly with any distinct and special ganglionic structure. In any concise account of it, I deem it impossible to surpass the definition of Mr. Morell : "An act of the will", says this eminent metaphysician, "embodies the effort of the whole man, implying, at the same time, intelligence, feeling, and force; physiologically speaking, this state of mind will stand in correlation with the total affection of the nervous system.... We regard it as an expression of the totality of our organic power, the whole governing the parts, and directing to the fulfilment of one purpose." $\dagger$

According to the account, then, which I have given of the vital operations, in the fulfilment of which the brain and nervous system mainly participate, reflex movements without consciousness issue from the grey matter of the spinal cord, and from the sympathetic ganglia; consensual actions flow from the distributive influence of the sensory ganglia; ideo-dynamic phenomena result, primarily, from limited action of the hemispherical ganglia; and those which are purely emotional come probably from the optic thalami and corpora striata. Voluntary acts proceed from the MaN.

I must allow-what, indeed, has already been concededthat in what I have advanced there is a great deal of speculation. I submit, however, that in any attempted correlation of psychology with physiology, it is impossible, in the present state of knowledge, ! avoid it; and, further, that for the attainment of clear and connected views of psychological medicine, it is good and useful to construct rational hypotheses, in default of estahlished and valid theories. Hypotheses, of course, must not have their value or their office mis-estimated; they cannot rightly form a rest, like an axiom; he who employs them must always be ready to modify or to give them up, when additional evidence appears to demand some such proceeding. Meanwhile, they serve to "colligate facts", and to fix the attention more searchingly upon phenomena. "There is a period in knowledge", says Crichton, "when hypotheses must be indulged in, if we mean to makc any progress. It is that period when the facts are too numerous to be recollected without general principles, and yet where the facts are too few to constitute a valid theory." $\ddagger$

\section{- Sur les Fonctions de Cervesu.}

+ Op. citne

\& Op. oitat. 
I would goand such of $\mathrm{my}$ hearems as aro inexperienced in discumions of thi hind, seainst the impreseion that ceience shows the soul, the conscious principle within us, to be susceptible of any true, actual dinsion. If there be one characteristic which more than another distinguishes the concoious soo from mere body, it is, I conceive, its absolute vinity. Hare we not the same assurance from pure conscioumes, that the me which thinks is not composed of parts, as we have from senso-consciousness that matter is an agregregte of atoms?

Distinctness in the organic instruments implies no corrosponding divisibility in the conscious principle which they subserve. To give expression upon this occasion to the abstract views which I entertain myself upon this subject, I would say that, in all psychical phenomens, the whole mind acts. Mental faculties are states of consciousnessphases only of the one undivided and indivisible mind. It is the whole mind which hears and sees; it is the same entire mind which receives ideas, and recalls them in momory; it is the one thinking entity that loves, fears, and hopes; it is still the same unity, the soul, that performs the highest intellectual operations, in abstracting, combining ideas, ressoning, and judging. Finally, and comprebensively, it is the immaterial spirit which takes cogniance of itself, which controls its own states, and which ตrmis.

\section{ON THE PATHOLOGY AND TREATMENT OF} LARYNGO-TRACHEAL INFLAMMATION.

\section{By ROBERT TURNER, M.D.}

[Continued from page 618.]

$\triangle$ COXPIETE statement of the arguments against tracheotomy in croup is, I believe, comprised in the subjoined extracts:-

"It is not necessary", says Dr. Williams (Library of Medicine, vol. iii, p. 61), "to discuss the question of the propriety of resorting to tracheotomy in croup; as it has been decisively negatived by Dr. Cheyne, Mr. Porter, and other of the best authorities. The trachea of young subjects is 80 small, vascular, and difficult to open; and, above all, the obstructing matter of croup so frequently extends into the bronchi, or cannot be dislodged, even from the trachea, through an incision, that the dangers are many, and the chances of success so few, that in general it can scarcely be said that the performance of the operation is justifiable."

"It has been proposed to perform the operation of bronchotomy", observes Dr. Maunsell (Evanson and Maunsell, On the Management and Diseases of Children, 5 th ed., p. 333), "in croup, with the objects, first, of admitting air to the lungs without the intervention of the larynx; and secondly, of remoring, mechanically, the false membrane from that passage. We have already stated that the inflammation of croup is not confined to the larynx, but extends over the whole bronchial mucous membrane; and Dr. Cheyne has shown that, in fatal cases, a space of more than two-eighths of an inch usually exists in the larynx, for the transmission of air. The patient, therefore, except in cases of sudden spasm, dies, not because air cannot have access to his lungs, but because these organs are unfitted, by their inflamed condition, from performing their own function. Consequently, bronchotomy is unnecessary for the effecting of the first object, and can do no good. As to removing the false membrane, if it could be accomplished, which those who are familiar with the morbid appearances in croup will doubt, the same ultimate objection applies, viz., that we till have the diseased condition of the lungs remaining, and to the remoral of that we contribute nothing by opening the wind-pipe; but, on the contrary, add a new cause of irritation."

"It (Group) is a disease", Dr. Chejne remarks (Cyclopadia of Practical Medicine, vol. iii, p. 23), "in which a murgical operation will only add to the danger to which, in the eccond atage, the patient is expoeed."

"When the aigms of approaching death have come on", arss Dr. Wateon (Lectures on the Privoiples and Precilion of Physic, 3nd ed., vol. i, p. 844), "lividity of the lipe, coldine of the skin, and a tendency to stupor, the queetion will obtrude itself, whether there may not etill be a chance of saring the patient by performing tracheotomy? In the first place, you will consider that the operation is much more difficult to execute upon children then upon edulte and is attended with more perplexing homorrhege. But there is a greater objection than this to tracheotomy in such cases - an objection which you will haro anticipatodnamely, the existence of the preternatural membrane, which often extends so far down, that air rould not be admitted into the lungs, even if an aperture in the windpipe were made at the lowest possible point. Another consideration, forbidding much hope of success from this expedient at any period of the disease, is that the ramifications of the bronchi and the ultimate air-cells get filled up with serous, or mucous or puriform matter, or even sometimes with a membranous exudation, whereby suffocation is effected in the lungs themselves. The membrane in the traches, being tubular, does not entirely exclude the air from these organs, but it does not admit it in sufficient quantity. Tracheotomy has again and again been practised in this complaint to no purpose; and I should be inclined to look upon it as absolutely hopeloss, but for two instances of its successful performance, recorded in the Medico-Chiruergical Transactions: the one achieved by Mr. Andre, and related by Dr. Farre, in the third volume; the other by Mr. Chevallier, in the sixth volume. They were both apparently hopeless cases. Immediate relief followed the operation in both, and the patients recovered perfectly. ... Unfortunately, we cannot tell, before death, to what degree or extent the preternatural membrane exists. All that can be said, I think, is that when dyspnoes and much croup come on suddenly and quickly, the disease is probably limited to the larynx and upper part of the windpipe; but that when the progress of the disorder is slower, and the croupy symptoms are not so well marked, it is more likely that a greater extent of the trachea, below the larynx, participates in the mischief. Our expectations of success from tracheotomy will vary accordingly. It affords a bad chance, at the best; but it affords, also, in many cases, the only chance."

Speaking of the diphtheritic form of the affection, Dr. Watson remarks: "The comparative freedom of the windpipe wonld encourage a trial of tracheotomy in these cases, when life seemed in jeopardy from impeded respiration; but the morbid condition of the blood, and the resulting character of the attendant fever, forbid the hope of such success from that mechanical remedy as it might otherwise promise."

On the same subject, Dr. Copland (Dictionary of Practical Medicine, art. (roup) thus expresses himself: "There does not seem to be a chance of success from this operation in any case wherein the treatment developed above has failed. The practitioner, however, may be called to a case so late in the disease, and where the suffocation is so imminent, that the propriety of haring recourse to it may be admitted; but, even in these, the chances are infinitely greater against than in farour of its success; and if benefit can be derived from any measure, it is as likely to accrue from the energetic exhibition of suitable emetics, $2 s$ from tracheotomy. Cases have doubtless been recorded of the success of the operation in croup; but these are so very few, compared with the number in which it has failed, that I perfectly agree with Goelis, Cheyne, Royer Collard, Porter, Wood, and many others, in concluding that it should seldom or never be attempted in this disease. Of the propriety of having recourse to it in certain states of laryngitis, etc., there can be no doubt; and it may, with some slight grounds of hope, be resorted to when croup is chiefly confined to the larynx and upper part of the trachen; also, perhapes, in some cases of its consecutive occurrence upon inflammation of the throat with membranous exudation; and when wo infer, from the general ajmptoms and the signs furnished by the stethoscope, that the bronchi and lungs are unaf fected: but in that period of the aimplo as roli as of mont 